\title{
Manajemen Logistik dan Persepsi Konsumen Lembaga terhadap Pemasaran Asparagus oleh Koperasi Tani Mertanadi di Desa Plaga Kecamatan Petang Kabupaten Badung
}

\author{
NI MADE INDRI DIANI, I GUSTI AGUNG AYU AMBARAWATI, \\ I NYOMAN GEDE USTRIYANA
}

\author{
Program Studi Agribisnis Fakultas Pertanian Universitas Udayana \\ Jalan PB Sudirman Denpasar 80232 \\ E-mail: indri_diani@yahoo.co.id \\ annie.ambarawati@gmail.com
}

\begin{abstract}
Logistic Management and Organizational Consumer's Perception on Asparagus Marketing by Farmer Cooperative
\end{abstract}

Asparagus is a commodity that is commonly sold for modern markets. Mertanadi farmer cooperative is the only cooperative in Bali that supply asparagus to many destinations including supermarkets, hotels, restaurants and other suppliers. The commodity is supplied by the cooperative members at Plaga Village, Petang district, Badung regency. The aims of this study are to find out logistic management of asparagus by Mertanadi farmer cooperative to the organizational consumers. This research was carried out to 17 organizational consumers of Mertanadi cooperative located in Denpasar city, Badung regency and Gianyar regency. Logistic management by the cooperative was analyzed using descriptive qualitative method, while the perceptions of the consumers to the commodity were analyzed using Likert scale. Result of the study shows that the Mertanadi farmer coopertaive has implemented the seven basic concepts of logistic management including planning, budgeting, procurement, warehousing and distribution, maintenance and deletion as well as controlling. Perceptions of the organizational consumers seen from product availability, product quality and price are categorized good. However there is one weakness, according to the consumers, that is the cooperative is not able to fulfil the entire demand. It is expected that the cooperative needs to manage to fulfil the whole consumer's demand.

Keywords: asparagus, logistics management, organizational consumer's perception

\section{Pendahuluan}

\subsection{Latar Belakang}

Sektor pertanian merupakan sektor yang mendapatkan perhatian cukup besar dari pemerintah. Sektor pertanian juga dapat menjadi basis dalam mengembangkan kegiatan ekonomi pedesaan melalui pengembangan usaha berbasis pertanian (Antara, 
2009). Pengelolaan usahatani hortikultura secara agribisnis dapat meningkatkan pendapatan petani dengan skala usaha yang kecil, karena nilai ekonomi komoditas hortikultura yang tinggi. Produk hortikultura terbesar adalah buah-buahan, diikuti sayuran, dan tanaman hias (Bappenas, 2014). Menurut Purwanto (2008) tuntutan konsumen terhadap produk hortikultura semakin meningkat, baik dari segi mutu, kuantitas, nilai gizi dan keamanan.

Perkembangan asparagus sebagai sub sektor hortikultura pada umumnya masih dalam skala perkebunan rakyat yang tumbuh dan dipelihara secara alami dan tradisional (Rahardi, 2001). Pada tahun 2011 dikembangkan program One Village One Product (OVOP) di Desa Plaga dengan dukungan dari Dinas Koperasi, UKM, Perindustrian dan Perdagangan dan Dinas Pertanian, Perkebunan dan Kehutanan Kabupaten Badung. Program ini mendukung pengembangan komoditi yang dipilih menjadi unggulan suatu daerah melalui perkuatan koperasi. Komoditi yang cocok untuk wilayah Desa Plaga yaitu asparagus. Asparagus merupakan salah satu jenis sayuran yang bersifat tahunan dan bagian yang dipanen dari tanaman ini adalah bagian rebung atau tunas muda (Rubatzky dan Mas. Y, 1999). Asparagus merupakan produk yang memiliki nilai jual tinggi atau high value product maka ada standar tertentu yang harus dipenuhi oleh petani seperti ukuran, mutu, bentuk dan lainnya (Bappenas, 2013).

Pasokan asparagus diterima dari petani anggota Koperasi Tani Mertanadi yang ada diwilayah Desa Plaga. Saat ini Koperasi Tani Mertanadi memasarkan asparagus ke pelanggan yang tergolong sebagai konsumen lembaga. Pelanggan Koperasi Tani Mertanadi terdiri dari perorangan atau organisasi yang terlibat dalam logistik pemasaran asparagus dari Koperasi Tani Mertanadi. Pelanggan bukanlah konsumen akhir sebagai pengkonsumsi, melainkan konsumen yang mempunyai kelembagaan untuk memasarkan kembali asparagus yang dibeli dari Koperasi Tani Mertanadi.

Rantai pasokan (supply chain) adalah saluran yang lebih panjang yang membentang dari bahan mentah hingga komponen sampai produk akhir yang dihantarkan ke pembeli akhir (Kotler dan Keller, 2009). Handfield (1999) mendefinisikan SCM merupakan integrasi atas kegiatan-kegiatan dalam suatu rantai pasok dengan hubungan yang diperbaiki, untuk mencapai suatu keunggulan bersaing yang berkelanjutan. Chopra \& Meindl (2007) berpendapat bahwa SCM mencakup manajemen atas aliran-aliran diantara tingkatan dalam suatu rantai pasok untuk memaksimumkan keuntungan total.

Manajemen logistik merupakan bagian dari manajemen rantai pasokan yang merencanakan dan mengatur aliran penyimpanan produk. Menurut Subagya (1994) fungsi manajemen logistik merupakan suatu proses yang terdiri dari perencanaan, penganggaran, pengadaan, penyimpanan dan pendistribusian, pemeliharaan, penghapusan dan pengendalian. Penyusunan sistem logistik ditujukan untuk meningkatkan keamanan, efisiensi, dan efektfitas pergerakan barang, informasi, dan uang mulai dari titik asal (point of origin) sampai dengan titik tujuan (point of 
destination) sesuai dengan jenis, kualitas, jumlah, waktu, dan tempat yang dikehendaki konsumen.

Pemasaran asparagus yang dilakukan Koperasi Tani Mertanadi memerlukan manajemen logistik agar tidak terjadi penyimpangan dalam melaksanakan kegiatannya. Banyaknya pelanggan dari Koperasi Tani Mertanadi memerlukan manajemen logistik yang baik agar produk dapat sampai ditangan pelanggan sesuai dengan jumlah pesanan dan tepat waktu yang diharapkan tanpa adanya kendala yang berarti. Manajemen logistik mencakup perencanaan, penganggaran, pengadaan, penyimpanan dan pendistribusian, pemeliharaan, penghapusan dan pengendalian. Manajemen logistik pada Koperasi Tani Mertanadi menarik untuk dikaji sehingga dapat membantu memecahkan permasalahan dalam bidang logistik. Penelitian ini memfokuskan pada manajemen logistik dalam pemasaran asparagus di Bali yaitu berjumlah 17 pelanggan, diantaranya restoran, villa, hotel, supermarket, dan supplier di daerah Kabupaten Badung, Gianyar, dan Kota Denpasar.

\subsection{Rumusan Masalah}

Berdasarkan latar belakang di atas, maka masalah yang dapat dikemukakan dalam penelitian ini adalah:

1. Bagaimana manajemen logistik asparagus yang dipasarkan oleh Koperasi Tani Mertanadi dalam memenuhi kebutuhan pelanggan?

2. Bagaimana persepsi pelanggan terhadap produk yang dipasarkan oleh Koperasi Tani Mertanadi di Desa Plaga Kecamatan Petang Kabupaten Badung?

\subsection{Tujuan Penelitian}

Tujuan penelitian ini adalah:

1. Untuk mengetahui manajemen logistik asparagus yang dilpasarkan oleh Koperasi Tani Mertanadi dalam memenuhi kebutuhan pelanggan.

2. Untuk mengetahui persepsi dari pelanggan terhadap produk yang dipasarkan oleh Koperasi Tani Mertanadi di Desa Plaga Kecamatan Petang Kabupaten Badung.

\subsection{Manfaat}

Manfaat dari penelitian ini adalah:

1. Bagi Koperasi Tani Mertanadi dapat dijadikan masukan dalam pengambilan keputusan dan kebijakan tentang melaksanakan kegiatan logistik.

2. Untuk peneliti dapat dijadikan sarana dalam menerapkan ilmu yang telah diperoleh pada perkuliahan dengan kenyataan dilapangan.

\subsection{Ruang Lingkup}

Ruang lingkup penelitian ini mencakup manajemen logistik yang terdiri atas perencanaan, penganggaran, pengadaan, penyimpanan dan pendistribusian, pemeliharaan, penghapusan dan pengendalian terhadap Koperasi Tani Mertanadi. 
Penelitian ini juga diteliti persepsi pelanggan terhadap asparagus yang dipasarkan oleh Koperasi Tani Mertanadi dan berapa besar selisih margin pemasaran asparagus. Penelitian ini dilakukan terhadap Koperasi Tani Mertanadi dan pelanggan dari Koperasi Tani Mertanadi di Desa Plaga Kecamatan Petang Kabupaten Badung.

\section{Metode Penelitian}

\subsection{Lokasi Penelitian}

Lokasi penelitian dilaksanakan di Koperasi Tani Mertanadi dan pelanggan dari Koperasi Tani Mertanadi di Desa Plaga, Kecamatan Petang, Kabupaten Badung, Provinsi Bali. Pemilihan lokasi ini dilaksanakan dengan metode purposive yaitu metode penentuan lokasi yang dilakukan secara sengaja terhadap 17 pelanggan yang bertempat di daerah Kabupaten Badung, Kabupaten Gianyar, dan Kota Denpasar.

\subsection{Jenis Data dan Sumber Data}

Jenis data dalam penelitian ini ada dua, yaitu kuantitatif dan kualitatif. Data kuantitatif yang digunakan dalam penelitian ini adalah jumlah (kg) pasokan asparagus ke pelanggan dan jumlah $(\mathrm{kg})$ pasokan asparagus dari anggota tani, penerimaan dan pembelian asparagus dalam kegiatan pemasaran, serta hasil jawaban kuesioner dari responden/konsumen lembaga Koperasi Tani Mertanadi. Data kualitatif yang digunakan dalam penelitian ini mencakup sejarah berdirinya Koperasi Tani Mertanadi, gambaran umum, dan struktur organisasi Koperasi Tani Mertanadi.

Sumber data dalam penelitian ini ada dua, yaitu primer dan sekunder. Data primer mencakup gambaran umum, jumlah asparagus yang disalurkan, persepsi pelanggan dan struktur organisasi dari Koperasi Tani Mertanadi. Data sekunder adalah data yang bersumber dari literatur atau publikasi yang berkaitan dengan penelitian.

\subsection{Metode Pengumpulan Data}

Metode pengumpulan data dalam penelitian ini menggunakan metode kuesioner, wawancara mendalam dan dokumentasi.

\subsection{Populasi, Sampel, dan Teknik Pengambilan Sampel}

Populasi dalam penelitian ini adalah semua pelanggan dari Koperasi Tani Mertanadi yang memasok asparagus yaitu sebanyak 17 pelanggan di Provinsi Bali. Seluruh populasi digunakan sebagai sampel, jumlah sampel yang akan diambil sebanyak 17 responden. Teknik pengambilan sampel menggunakan metode sampling jenuh, dimana semua populasi dijadikan sebagai sampel.

\subsection{Variabel dan Pengukuran Variabel}

Variabel yang digunakan dalam penelitian ini dibagi menjadi dua yaitu, manajemen logistik dan persepsi konsumen. Variabel manajemen logistik mencakup tujuh indikator yaitu perencanaan, penganggaran, pengadaan, penyimpanan dan 
pendistribusian, pemeliharaan, penghapusan, dan pengendalian. Variabel persepsi konsumen mencakup tiga indikator yaitu ketersediaan produk, kualitas produk, dan harga.

\subsection{Batasan Operasional}

1. Manajemen logistik adalah aktifitas yang dilakukan dalam perencanaan, penganggaran, pengadaan, penyimpanan dan pendistribusian, pemeliharaan, penghapusan dan pengendalian asparagus dari Koperasi Tani Mertanadi sampai ke pelanggan sesuai dengan permintaan.

2. Pelanggan adalah orang atau organisasi yang terlibat dalam logistik dari Koperasi Tani Mertanadi. Pelanggan yang memiliki kelembagaan untuk bisa memasarkan kembali produk yang dibeli.

3. Persepsi pelanggan adalah penilaian responden/konsumen lembaga terhadap ketersediaan produk, kualitas produk, dan harga dari asparagus.

\subsection{Analisis Data}

Analisis data yang digunakan dalam penelitian ini adalah:

\subsubsection{Analisis deskriptif kuantitatif}

Metode analisis deskriptif kuantitatif digunakan untuk menjawab tujuan penelitian pertama yaitu, manajemen logistik asparagus oleh Koperasi Tani Mertanadi dalam memenuhi permintaan pelanggan yang dilihat dari perencanaan, penganggaran, pengadaan, penyimpanan dan pendistribusian, pemeliharaan, penghapusan dan pengendalian.

\subsubsection{Penilaian skala Likert}

Persepsi pelanggan terhadap asparagus akan dijawab dengan menggunakan penilaian skala Likert. Pengukuran dilakukan dengan metode skoring dengan memberikan skor pada tingkat kesetujuan dan ketidaksetujuan responden terhadap masing-masing pernyataan dengan menggunakan skor dari 1, 2, 3, 4, 5. Skor 1 artinya sangat tidak baik, skor 2 artinya tidak baik, skor 3 artinya sedang, skor 4 artinya baik, dan skor 5 artinya sangat baik. Data yang diperoleh dari hasil pengukuran tersebut selanjutnya diproses untuk memperoleh interval kelas dengan rumus dibawah ini (Sudjana, 2005)

$$
\mathrm{i}=\frac{\mathbf{R}}{\mathbf{k}}
$$

Keterangan:

$\mathrm{i}=$ interval kelas

$\mathrm{R}=$ selisih nilai pengamatan tertinggi dengan terendah

$\mathrm{k}=$ jumlah interval kelas 
Berdasarkan rumus interval kelas diatas, data selengkapnya dapat dilihat sebagai berikut.

$$
\mathrm{i}=\frac{\text { Skor maksimum }- \text { skor minimum }}{5}=\frac{5-1}{5}=0,8 \text {. }
$$

Panjang interval kelas tersebut selanjutnya didistribusikan ke masing-masing kelas sehingga ditemukan rata-rata skor dari skor maksimal pada masing-masing kategori seperti terlihat pada tabel 1.

Tabel 1.

Pencapaian Rata-rata Skor serta Kategori Persepsi

\begin{tabular}{cc}
\hline Pencapaian rata-rata skor & Kategori \\
\hline $1-1,8$ & Sangat Tidak Baik \\
$>1,8-2,6$ & Tidak Baik \\
$>2,6-3,4$ & Sedang \\
$>3,4-4,2$ & Baik \\
$>4,2-5$ & Sangat Baik \\
\hline
\end{tabular}

\section{Hasil dan Pembahasan}

\subsection{Manajemen Logistik Asparagus}

Koperasi Tani Mertanadi bekerjasama dengan petani asparagus di Desa Plaga untuk memasok permintaan asparagus dari pelanggan Koperasi Tani Mertanadi. Pelanggan dari Koperasi Tani Mertanadi di Bali yang konsisten membeli asparagus hanya berjumlah 17 pelanggan.

Pelanggan yang rutin memesan asparagus di Bali tersebar di wilayah Kota Denpasar, Kabupaten Badung dan Kabupaten Gianyar yang mencakup supermarket, restoran, hotel dan villa, dan supplier. Asparagus yang dipasarkan oleh Koperasi Tani Mertanadi dipasok lebih banyak ke supermarket, yaitu sebanyak $5.044 \mathrm{~kg}$ atau $57 \%$ sedangkan asparagus dipasok paling sedikit ke restoran, yaitu hanya $48 \mathrm{~kg}$ atau 0,5\% dari total pasokan asparagus selama bulan Februari sampai dengan bulan April tahun 2016.

Manajemen logistik dari Koperasi Tani Mertanadi melakukan 7 kegiatan yang terdiri atas perencanaan, penganggaran, pengadaan, penyimpanan dan pendistribusian, pemeliharaan, penghapusan, serta pengendalian dalam melakukan pemasaran asaparagus dari Koperasi Tani Mertanadi ke pelanggan.

\subsubsection{Perencanaan}

Perencanaan pada awal berdirinya Koperasi Tani Mertanadi tahun 2009 tidak merencanakan untuk mengembangkan dan memasarkan asparagus. Koperasi Tani Mertanadi hanya melakukan kegiatan usaha menjual produk pendukung pertanian, seperti pupuk dan obat-obatan. Koperasi Tani Mertanadi pada tahun 2010 mendapat bantuan dari PEMDA Badung dan Pemerintah Taiwan melalui program One Village 
One Product (OVOP). Program OVOP yang diibahkan pada Koperasi Tani Mertanadi memiliki unit usaha baru, yaitu menjual berbagai komoditi sayuran yang salah satunya adalah asparagus. Petani asparagus menjual hasil panen asparagus ke Koperasi Tani Mertanadi. Harga asparagus ditetapkan oleh Koperasi Tani Mertanadi sesuai dengan kesepatan anggota. Harga disesuaikan menurut grade.

Grade Super dibeli Rp 45.000,-/kg dan dijual kembali a Rp 75.000,-/kg,

Grade A Rp 35.000,-/kg dijual kembali seharga Rp 65.000,-/kg,

Grade B Rp 25.000,-/kg dan dijual kembali seharga Rp 45.000,-/kg,

Grade C Rp 20.000,-/kg dan dijual kembali seharga Rp 35.000,-/kg,

Non grade (rijek) Rp 20.000,-/kg dan dijual kembali seharga Rp 40.000,-/kg.

\subsubsection{Penganggaran}

Anggaran yang disiapkan Koperasi Tani Mertanadi untuk melunasi pembelian asparagus dari anggota tani yaitu dari hasil penjualan asparagus ke pelanggan. Koperasi Tani Mertanadi membutuhkan dana yang sangat banyak untuk membeli asparagus. Pasokan yang diterima oleh Koperasi Tani Mertanadi memerlukan anggaran biaya sebesar Rp 572.409.800,- untuk membeli asparagus pada bulan Februari sampai dengan April.

\subsubsection{Pengadaan}

Pengadaan asparagus di Koperasi Tani Mertanadi berjumlah $\pm 5000 \mathrm{~kg}$ asparagus setiap bulannya. Pasokan asparagus didapat dari anggota petani yang berada di wilayah Desa Plaga. Nilai margin $(\mathrm{Rp} / \mathrm{kg})$ asparagus berbeda pada setiap grade. Nilai margin terbesar untuk grade asparagus dihasilkan dari asparagus grade $\mathrm{S}$ sebesar Rp 30.000,00/kg, sedangkan margin terkecil dihasilkan dari asparagus grade C sebesar Rp 15.000,00/kg. Selisih harga tersebut Koperasi Tani Mertanadi mampu mendapatkan keuntungan.

Tabel 2.

Perbandingan Pembelian dan Penerimaan Asparagus

Bulan Februari-April tahun 2016

\begin{tabular}{lcrrrrrr}
\hline \multirow{2}{*}{ Bulan } & \multicolumn{5}{c}{ Asparagus (Rp) } & \multirow{2}{*}{ Total } \\
\cline { 2 - 6 } & $\mathrm{S}$ & $\mathrm{A}$ & $\mathrm{B}$ & $\mathrm{C}$ & non grade & \\
\hline Pembelian & 256.653 .000 & 164.563 .000 & 85.330 .000 & 55.095 .800 & 10.768 .000 & 572.409 .800 \\
Penerimaan & 427.972 .500 & 314.610 .000 & 128.385 .000 & 104.814 .500 & 21.536 .000 & 997.318 .000 \\
\hline Selisih & 171.319 .500 & 150.047 .000 & 43.055 .000 & 49.718 .700 & 10.768 .000 & 424.908 .200 \\
\hline
\end{tabular}

Pada tabel 2 dapat dilihat perbedaan selisih pembelian dengan penerimaan. Pembelian asparagus dari petani dari Bulan Februari sampai Bulan April sebesar Rp 572.409.800,- sedangkan untuk penerimaan yang didapat dari penjualan asparagus sebesar Rp 997.318.000,-. Selisih pembelian dengan penerimaan Koperasi Tani Mertanadi selama 3 bulan yaitu sebesar Rp 424.908.200,-. Koperasi Tani Mertanadi 
rata-rata memperoleh penerimaan atau keuntungan kotor sebesar Rp 141.636.067,/bulan.

\subsubsection{Penyimpanan dan penditribusian}

Koperasi Tani Mertanadi melakukan kegiatan penyimpanan dengan menggunakan ruangan pendingin atau cold stroge pada suhu $22^{\circ} \mathrm{C}$. Asparagus yang sudah disortir akan disimpan pada cold stroge, jika ada pemesanan dari pelanggan maka asparagus yang pertama disimpan akan dikeluarkan/dipacking terlebih dahulu. Koperasi Tani Mertanadi melakukan metode first in-first out. Metode ini dilakukan mengingat bahan baku yang bersifat tidak tahan lama dan terus mengalami penambahan kuantitas setiap waktu, sehingga Koperasi Tani Mertanadi mengeluarkan barang sesuai dengan urutan pembeliannya.

Pendistribusian asparagus dilakukan pada hari Senin sampai Sabtu sesuai jam kerja karyawan di Koperasi Tani Mertanadi. Asparagus didistribusikan ke 17 pelanggan yang terdiri dari supermarket (Pepito, Tiara Dewata, Bintang Ubud, Lotte Mart, dan Papaya), restoran (Bale Udang Ubud dan MM Catring), hotel dan villa (Westin Hotel, Villa Air Bali), dan supplier (Ari Karomah, Driya Suwindriya, Dwi Jaya, Irene, Pak Lombok, Wayan Sumatra, Tarigan, dan Pak Ari). Pendistribusian atau pemasaran asparagus ke pelanggan melalui jalur darat menggunakan mobil cold-box dengan jarak tempuh terjauh pada Hotel Westin Nusa Dua yaitu $75 \mathrm{~km}$, sedangkan untuk jarak tempuh terdekat pada supermarket Bintang di Ubud yaitu 39 $\mathrm{km}$.

Pelanggan yang tergolong supplier akan menjual kembali asparagus yang dibeli dari Koperasi Tani Mertanadi ke hotel-hotel dan restoran yang menjadi mitra usahanya. Pasokan asparagus yang didistribusikan ke pelanggan lebih banyak ke supermarket yaitu 57,1\% untuk bulan Februari sampai dengan bulan April tahun 2016.

\subsubsection{Pemeliharaan}

Pemeliharaan yang dilakukan untuk untuk mempertahankan kondisi teknis, daya guna dan hasil barang inventaris, Koperasi Tani Mertanadi rutin membersihkan terlebih dahulu alat-alat dan tempat bekerja, serta merawat alat ukur/timbang, alat press serta gudang penyimpanan digunakan secara wajar dengan tidak menggunakan secara berlebihan, atau digunakan sesuai fungsinya.

\subsubsection{Penghapusan}

Penghapusan atau pembebasan barang yang mengalami kerusakan yang tidak diperbaiki lagi yaitu meliputi produk yang sudah busuk saat penyimpanan, alat penunjang kerja yang memiliki umur ekonomis yang pendek seperti gunting, pisau, serta alat untuk bersih-bersih saat memulai dan mengakhiri kegiatan sortir dan packing. 


\subsubsection{Pengendalian}

Pengendalian yang dilakukan oleh Koperasi Tani Mertanadi tidak hanya mengawasi kinerja karyawan tetapi juga mengawasi cara bertani petani asparagus agar cara penanaman dan perawatan dilakukan dengan benar sehingga menghasilkan asparagus yang sesuai dengan standar yang ditetapkan oleh Koperasi Tani Mertanadi. Pengawasan juga dilakukan terhadap pelanggan yang belum melunasi biaya pemesanan.

\subsection{Persepsi Pelanggan}

Persepsi pelanggan terhadap pemasaran asparagus oleh Koperasi Tani Mertanadi mengenai ketersediaan produk, kualitas, dan harga asparagus tergolong baik. Persepsi pelanggan terhadap ketersediaan produk, kualitas dan harga terhadap pemasaran asparagus dari Koperasi Tani Mertanadi dapat dilihat pada tabel 3.

Tabel 3.

Hasil Penilaian Persepsi Pelanggan terhadap Pemasaran Asparagus

\begin{tabular}{|c|c|c|c|}
\hline No & Persepsi & Pencapaian rata-rata skor & Kategori \\
\hline 1 & Ketersediaan produk & 3,79 & Baik \\
\hline 2 & Kualitas & 4,15 & Baik \\
\hline 3 & Harga & 4,08 & Baik \\
\hline & Rata-rata & 4,01 & Baik \\
\hline
\end{tabular}

Persepsi pelanggan terhadap persediaan produk termasuk dalam katagori baik dengan skor 3,79. Penilaian dari segi kualitas, asparagus mencapai skor 4,15 dengan kategori baik. Skor untuk kualitas asparagus memiliki nilai terbesar. Persepsi konsumen lembaga terhadap harga aspagus mencapai skor 4,08 dengan kategori baik. Harga asparagus tergolong mahal, hal ini dikarenakan pemasaran asparagus belum luas dan hanya dijual di pasar modern dan disajikan direstoran.

Penilaian menyeluruh persepsi pelanggan terhadap pemasaran asparagus oleh Koperasi Tani Mertanadi menunjukan kualitas asparagus memiliki nilai skor yang tinggi, namun Koperasi Tani Mertanadi masih memiliki kelemahan dari segi ketersediaan produk.

\section{Kesimpulan dan Saran}

\subsection{Kesimpulan}

Manajemen logistik dan persepsi pelanggan terhadap pemasaran asparagus oleh Koperasi Tani Mertanadi dapat disimpulkan sebagai berikut.

1. Secara umum Koperasi Tani Mertanadi sudah melakukan tujuh kriteria manajemen logistik yaitu perencanaan, penganggaran, pengadaan, penyimpanan dan pendistribusian, pemeliharaan, penghapusan dan 
pengendalian. Koperasi Tani Mertanadi mempunyai kendala dalam pengadaan, dimana permintaan pelanggan belum $100 \%$ terpenuhi, pasokan asparagus terbanyak didistribusikan ke supermarket yaitu sebanyak $5.044 \mathrm{~kg}$ atau $57 \%$ dari total asparagus yang didistribusikan ke pelanggan selama bulan Februari sampai dengan April tahun 2016.

2. Persepsi dari pelanggan tentang pasokan asparagus dari Koperasi Tani Mertanadi tergolong baik. Persepsi pelanggan terhadap ketersediaan produk sebesar 3,79 tergolong baik. Persepsi pelanggan terhadap kualitas asparagus sebesar 4,15 tergolong baik, dan persepsi pelanggan terhadap harga asparagus sebesar 4,08 tergolong baik.

\subsection{Saran}

Saran yang dapat diberikan adalah manajemen logistik pada Koperasi Tani Mertanadi perlu dibenahi lagi terutama pada bagian pengadaan dengan memperhatikan pasokan asparagus dan menghimbau anggota tani koperasi agar semua hasil asparagus diserahkan kepada Koperasi Tani Mertanadi. Sistem pencatatan asparagus yang diterima dari anggota tani dan dipasarkan ke pelanggan juga perlu diperhatikan.

\section{Daftar Puskata}

Antara, M. 2009. Pertanian, Bangkit atau Bangkrut?. Denpasar: Arti Foundation.

Chopra, S., dan Meindl, P. 2007. Supply Chain Management: Strategy, planning, and operations. New Jersey: Pearson Prentice Hall.

Kementerian PPN/Bappenas RI. 2013. Warta KUMKM 2013. Internet. http://bappenas.go.id/files/9914/2683/7295/Warta_KUMKM_2013_Vol1._No2 .pdf. Diunduh tanggal 28 Februari 2016.

Kementrian PPN/Bappenas RI. 2014. Hortikultura, Profil Pangan Dan Pertanian. Internet. http://www.bappenas.go.id/files/6213/5216/0347/bab-5.pdf. Diunduh tanggal 28 Januari 2016

Kotler P. dan Keller K. 2009. Manajemen Pemasaran. Edisi 13. Jakarta: Erlangga

Handfield, R.B dan Nichols, E.L. 1999. Introduction to Supply Chain Management. New Jersey: Pearson Prentice Hall.

Rahardi, F., Rony, P. dan Asiani, B., 2001. Agribisnis Tanaman Sayur. Jakarta: Penebar Swadaya.

Rubatzky, V. E. dan Mas Y. 1999. Sayuran Dunia, Prinsip, Produksi dan Gizi Jilid Ketiga. Jakarta

Subagya, M.S. 1994. Manajemen Logistik Cetakan Keempat. Jakarta: Haji Masagung.

Sudjana. 2005. Metoda Statistika. Bandung: Penerbit Tarsito.

Purwanto. 2008. Metodologi Penelitian Kuantitatif untuk Psikologi dan Pendidikan. Yogyakarta: Pustaka Pelajar. 